\title{
Implicações do desenvolvimento econômico no trabalho, ambiente e saúde em comunidades portuárias no Ceará, Brasil
}

\author{
The implications of economic development on work, the \\ environment and health in port communities in the State of Ceará, \\ Brazil
}

\author{
Maria das Graças Viana Bezerra ${ }^{1}$ \\ Raquel Maria Rigotto ${ }^{2}$ \\ Vanira Matos Pessoa ${ }^{3}$ \\ Flora Viana Elizeu da Silva ${ }^{4}$
}

\footnotetext{
${ }^{1}$ Secretaria Municipal de Saúde de Eusébio. R. Irmã Ambrosina 81, Centro. 61.760-000 Eusébio CE Brasil.viannamaria@yahoo. com.br

2 Departamento de Saúde Comunitária, Centro de Ciências da Saúde, Universidade Federal do Ceará (UFC).

${ }^{3}$ Fundação Oswaldo Cruz. ${ }^{4}$ Instituto de Ciências do Mar, UFC.
}

\begin{abstract}
This paper discusses aspects of economic development and the implications on work, the environment and health in the surrounding communities of the Industrial and Harbor Complex in Pecém in the State of Ceará. Qualitative research was adopted as the methodological strategy, by conducting participatory research with document analysis and a focus group. The reports of the subjects involved in the fieldwork were analyzed as being representative of their perceptions regarding the changes occurring in the territory and the impacts on health. Results observed in the use and appropriation of land by entrepreneurs are based on a belief in progress and development, contradicting the way of living, producing and interacting with nature submitted by the community that seeks to resist this intervention supported by social movements. These changes are out of step with the development of other public policies to mitigate the impacts with regard to environmental protection of the territory and the promotion of the health of this population.
\end{abstract}

Key words Environmental health, Occupational health, Economic development
Resumo Este estudo discute aspectos do desenvolvimento econômico e as implicações no trabalho, ambiente e saúde em comunidades circunvizinhas ao Complexo Industrial e Portuário do Pecém no Ceará. Adotamos como estratégia metodológica a investigação qualitativa, realizando uma pesquisa participante, com análise documental e grupo focal. Os discursos dos sujeitos envolvidos no trabalho de campo foram analisados como representação de suas percepções acerca das transformações ocorridas no território e as repercussões sobre a saúde. Observamos nos resultados, que o uso e a apropriação do território, pelos empreendedores, se fundamentam na crença do progresso e do desenvolvimento, contradizendo com o modo de viver, produzir e interagir com a natureza, apresentado pela comunidade que tenta resistir a essa intervenção apoiada pelos movimentos sociais. Tais transformações estão em descompasso com o desenvolvimento de outras políticas públicas destinadas a mitigar os impactos, no que se refere à proteção ambiental desse território e à promoção da saúde dessa população.

Palavras-chave Saúde ambiental, Saúde do trabalhador, Desenvolvimento econômico 


\section{Introdução}

As significativas transformações introduzidas nos territórios pelos processos produtivos incidem sobre os condicionantes da saúde e provocam repercussões sobre o processo saúde-doença. As práticas sociais dominantes de apropriação do território e de seus recursos perpetuam um cenário de desigualdades e conflitos ${ }^{1}$, em que prevalecem os interesses econômicos em detrimento da proteção à saúde e ao ambiente.

Visando o crescimento econômico, o governo federal tem promovido a expansão do setor industrial, diminuindo os entraves administrativos e burocráticos, facilitando o investimento do capital privado com subsídios, através do Programa de Aceleração do Crescimento (PAC), estratégia para fortalecer o modelo de desenvolvimento vigente. Com isso, muitos empreendedores têm investido no setor de geração de energia para as novas indústrias.

Surgem, nesse contexto, em pequenas comunidades, cenários pouco habituais até então, formados pela implantação de grandes empreendimentos. Estes modificam a paisagem do lugar, alteram a dinâmica do cotidiano das famílias e a sua organização local, transformando as condições de trabalho e introduzindo novas relações.

Os investimentos do PAC têm contemplado a região Nordeste, e nesta o Ceará, em que estão sendo implantados empreendimentos da cadeia do ferro/aço e da bauxita/alumínio - eletrointensivas. As indústrias instaladas e ou previstas para o complexo industrial e portuário do Pecém/Ceará (CIPP) são as termelétricas (uma a gás natural e outra a carvão mineral), uma siderúrgica com coqueria e uma refinaria de petróleo. Ocorre que esses processos produtivos se legitimam com a marca de geradores de emprego e renda e são utilizados como uma estratégia para realçar o desenvolvimento econômico do estado. Essa situação confronta com as notícias difundidas pelo governo estadual e pela mídia, de um modo geral, que enfocam positivamente o desenvolvimento econômico, a geração de empregos e as melhorias na infraestrutura, facilitando a aceitação desses empreendimentos pelos cidadãos que não vivenciam de perto esta realidade.

Os planos de governo do Ceará, conforme o modelo hegemônico de desenvolvimento, apresentam como principais vertentes, os incentivos ao agronegócio, à promoção do turismo e ao desenvolvimento industrial. Rigotto ${ }^{2}$ discute a sustentabilidade do processo de desenvolvimento no Ceará, e afirma que o Nordeste após 1960, vem assumindo um novo papel no contexto da divisão internacional do trabalho no país, patrocinado pelo Estado, passando de tradicional região produtora de bens de consumo não duráveis - têxtil e alimentar, principalmente - para bens intermediários.

O modelo de desenvolvimento que predomina no Ceará nas últimas décadas coaduna-se com programas e projetos desenvolvidos pelo governo federal e agências multilaterais. São exemplos de agências de fomento o Banco Internacional de Reconstrução e Desenvolvimento BIRD e o Banco Interamericano de Desenvolvimento (BID), atuando principalmente nas áreas de educação, saúde e desenvolvimento econômico entre outras. A parceria estabelecida entre as agências e o Estado confere-lhes mais poder, ocasionando uma luta de poder desigual ante pequenas comunidades moradoras dos territórios "contemplados" com iniciativas desenvolvimentistas. Estes grupos locais tornam-se vulnerabilizados, porque há nesse processo a destruição das relações entre povos tradicionais, seus territórios e culturas ${ }^{3}$.

Young e Lustosa ${ }^{4}$ afirmam que, no início dos anos de 1960, muitos países da América Latina haviam adotado políticas econômicas visando à industrialização via substituição de importações, baseados na produção de bens de consumo não duráveis para o mercado interno. Nas duas últimas décadas surge a necessidade de formas mais complexas de industrialização com a produção de bens de capital, intermediários e de consumo duráveis. Os autores consideram que o excedente gerado pelos ganhos de produtividade, advindos do progresso tecnológico, não são distribuídos igualmente entre todos e sim apropriados pelas camadas mais ricas da população, que também são os donos dos meios de produção, tendo o crescimento econômico acentuado ainda mais as disparidades de renda e riqueza entre as classes sociais na América Latina. Essa situação é também reproduzida para a realidade do Nordeste, especificamente para o Ceará.

As políticas sociais, contudo, não têm caminhado na mesma velocidade da política econômica, como o caso do setor saúde, operacionalizada pelo Sistema Único de Saúde -SUS, para dar respostas efetivas, considerando as novas demandas para o setor. Observamos que não há um planejamento do impacto na saúde da população, nem levantamento da necessidade de se adequar a oferta de serviços de saúde de qualidade para os expostos aos novos meios de produção.

Na década de 1990, mais de 600 novas indústrias foram atraídas para o Ceará, consolidando 
uma política de incentivo à industrialização, em que a indústria é colocada como caminho para o desenvolvimento, justificado pela necessidade de geração de emprego e também por ser atividade menos vulnerável aos limites impostos pelo semiárido ${ }^{2}$.

As novas indústrias situam-se no CIPP, que possui um porto de médio porte construído para exportar produtos siderúrgicos e derivados de petróleo, e também exporta e importa produtos da agroindústria, madeira, minerais, calçados, couros, metalurgia e indústria têxtil. A infraestrutura portuária tem merecido especial atenção do governo brasileiro, que tem financiado estudos para o dimensionamento e a avaliação das deficiências dos portos no Brasil, visando quantificar os investimentos necessários para a solução das demandas que se apresentam, determinando as dificuldades físicas e financeiras que possam estar atrasando a plena execução das obras constantes do Programa de Aceleração do Crescimento (PAC).

A expansão do CIPP, com a implantação desses empreendimentos, faz parte da política intensiva de atração de capital externo do governo estadual, fomentado pelo governo federal através do PAC, visando atrair indústrias para a formação do polo metalmecânico.

No território de expansão do CIPP residem comunidades do município de São Gonçalo do Amarante/CE, que é uma área decretada para desapropriação. Essas comunidades têm um modo de viver em que produzem alimentos para o autoconsumo nos quintais, que é decisivo para a sua segurança alimentar. O modo de produzir está enraizado na história vivida pelas famílias e pela comunidade, garantindo a diversidade, a qualidade e a disponibilidade de alimentos durante todo o ano. Soma-se a produção dos alimentos, a preservação da paisagem, do ambiente e da diversidade cultural, o que contribui para o fortalecimento da ocupação territorial e a manutenção do tecido social. O objetivo deste manuscrito é discutir aspectos do desenvolvimento econômico e as implicações no trabalho, ambiente e saúde em comunidades circunvizinhas ao Complexo Industrial e Portuário do Pecém, no Ceará.

\section{Metodologia}

Realizamos este estudo em um município da Região Metropolitana de Fortaleza, denominado São Gonçalo do Amarante/Ceará. Este situa-se na faixa litorânea, uma região rica em lagoas, praias e dunas e também é sede do CIPP. O município tem uma significativa extensão do seu território destinada à implantação de grandes empreendimentos, pertencentes ao bloco de investimentos em infraestrutura do PAC, no eixo de produção de energia e siderurgia.

Priorizamos uma comunidade, dentre as existentes na área de abrangência do CIPP e no entorno, formada por diversos conglomerados habitacionais, cerca de 15 deles, onde habitam em média 1400 pessoas. Essa comunidade solicitou à Universidade Federal do Ceará, a participação em um encontro organizado pelos movimentos sociais, para prestar esclarecimentos às pessoas moradoras no entorno das termelétricas e siderúrgicas, sobre os riscos à saúde decorrentes da instalação desses empreendimentos. Esse contato inicial foi decisivo para o delineamento das proposições acerca da necessidade do desenvolvimento de estudos nessa comunidade.

Adotamos a abordagem qualitativa que abrange a subjetividade inerente aos processos e relações sociais ${ }^{5}$, compreende fenômenos específicos e delimitáveis pelo seu grau de complexidade interna. Utiliza para a investigação, imagens, símbolos, sendo, porém, o material primordial a palavra, que expressa a fala cotidiana, seja nas relações afetivas e técnicas, seja nos discursos intelectuais ou burocráticos ${ }^{6}$.

Realizamos uma pesquisa participante, que tem sua origem na psicologia social de Kurt Lewin e vincula os processos de investigação a uma transformação social. Esses processos são baseados nas necessidades de grupos sociais politicamente marginalizados, e têm como objeto o processo de aprendizagem dos que fazem parte da pesquisa.

Utilizamos uma combinação de diferentes técnicas de investigação qualitativa, a saber: análise documental, a observação livre e o grupo focal. O grupo focal é uma técnica simples, rápida e distingue-se por suas características próprias, principalmente pelo processo de interação grupal, que é uma resultante da procura de dados facilitando a formação de ideias novas e originais ${ }^{7}$. Este pode ser utilizado no entendimento de como se formam as diferentes percepções e atitudes acerca de um fato, prática, produto ou serviços.

Buscamos informações nas bases de dados secundários, institucionais e governamentais relacionadas às políticas públicas de saúde, informações demográficas e os sistemas de informação em saúde da Secretaria Municipal.

Em paralelo, visitamos a comunidade e realizamos uma reunião inicial para a apresentação e 
discussão da pesquisa, momento em que foram esclarecidas as dúvidas, elaborado um cronograma de idas a comunidade e cinco outras reuniões que objetivaram a: debater a problemática local identificando os elementos do modo de vida bem como as repercussões sobre a saúde advindas com as transformações vividas no território; e contribuir com a discussão sobre a relação existente entre a saúde, desenvolvimento, trabalho e ambiente. Neste processo elaboramos um roteiro de perguntas sobre os temas em questão, que orientou a discussão em grupo.

Realizamos um grupo focal com treze participantes com idades entre 18 e 75 anos, sendo: um agricultor, duas donas de casa, duas profissionais de saúde, uma professora, três estudantes, duas lideranças comunitárias, uma artesã e um trabalhador das empresas. Adotamos como forma de registro do material empírico a gravação de voz e anotações em diário de campo.

Apreendemos o material empírico a partir da análise de discurso, que, de acordo com Gill ${ }^{8}$, é o nome dado a uma variedade de diferentes enfoques no estudo de textos, desenvolvida a partir de diferentes tradições teóricas e diversos tratamentos em diferentes disciplinas. A autora ressalta que não existe uma única "análise de discurso", mas muitos estilos diferentes de análise, e todos reivindicam o nome.

Realizamos leituras aprofundadas das falas transcritas, em seguida submetemos as falas a uma categorização temática, reunindo-as em categorias de análise organizadas.

A pesquisa foi aprovada pelo Comitê de Ética em Pesquisa da Universidade Federal do Ceará. Todos os sujeitos envolvidos concordaram em participar mediante assinatura de termo de consentimento.

A discussão a seguir, resulta de um mosaico em que os questionamentos funcionam como fio condutor e os discursos representam a percepção dos sujeitos sobre a realidade vivida.

\section{Resultados e discussão}

\section{A chegada do desenvolvimento: transformações e impactos no modo de vida decorrentes da implantação dos novos processos produtivos sob a visão da comunidade}

Conforme relatos do grupo, a chegada do desenvolvimento traz um esteio de destruição que se inicia pelas desapropriações e avança sobre a natureza. É claro, para os participantes do grupo, quem são os beneficiários desse modelo. Ressentem-se da imposição e intervenção sobre suas vidas, reconhecem o fato de não terem sido consultados sobre os seus destinos. Tal situação evidencia a não participação nos processos decisórios.

Quem está interessado no desenvolvimento é o governo, são os políticos. Quem estão se beneficiando são eles mesmos. As fábricas vão trazer muito dinheiro para eles. O governo e grandes empresas, como eles dizem que essa (siderúrgica) é a maior do Brasil.

O que é esse desenvolvimento que chegou sem convite dos moradores? Nenhum fez convite, ligou ou pediu a Deus para ele (o desenvolvimento) vir.

Eu entendo que eles só querem trazer o mal para a gente, porque a poluição prejudica a nossa saúde.

Desenvolvimento tem o lado positivo para os governantes e negativo para nós.

Esse tal de desenvolvimento não é desenvolvimento, e sim a morte. As desapropriações levaram muitas pessoas à morte.

As alegações para tal destruição se revertem de um discurso em que o "bem comum", a geração de empregos, o desenvolvimento econômico para o estado e a necessidade de remoção dos "obstáculos" justifica tal proceder. É dessa forma que o governo do Estado do Ceará denomina as comunidades do CIPP, que resistem e lutam pelo direito de permanecer na terra tradicionalmente ocupada.

Ribeiro 3 afirma que "desenvolvimento" é um dos discursos mais inclusivos no senso comum e na literatura especializada. A plasticidade do discurso sobre desenvolvimento é central para assegurar sua viabilidade continuada; ele está sempre em processo de transformação, de cumprir promessas. Os que relutam em se tornar sujeitos do desenvolvimento se deparam com a apropriação do poder local pelos empreendedores, em que o seu destino é suscetível de ser sequestrado por um grupo organizado de pessoas, fato difícil de conceber antes do projeto de desenvolvimento.

\section{Transformações no modo de vida: uma necessidade ou uma imposição do desenvolvimento?}

Onde tem aquela fábrica de cimento, desce uma poeira danada no meio do mundo. Os que moram por ali estão em tempo de não aguentar de tanta zoada e poeira.

A nossa preocupação é com essas empresas que ainda estão para vir. E quando elas chegarem, co- 
meçarem a desmatar, começarem a trabalhar [...] essa siderúrgica... [...] vai chegar mais preocupação! Quem acaba mais a área da saúde é a preocupação. A gente pensa, a gente sente, aí vai mexer com a pressão e aí por diante.

Eu me lembro o tempo do meu pai, quando ele conseguiu um pedaço de chão para criar os filhos, os netos. Será que as crianças vão poder fazer isso com seus filhos (no futuro)? Eu acredito que não! [...] tudo que a gente quer é permanecer aqui, criar os filhos aqui.

[...] essa pressão que a gente está passando hoje, esse momento de angústia, de não poder dizer: a gente vai continuar aqui, vai viver até o fim da nossa vida aqui! A gente não tem mais como fazer isso, sabe?

Os participantes demonstram as preocupações com a vinda das outras empresas que trarão novos problemas e impactos maiores. O crescimento extensivo orientado verticalmente pelo Estado e pelas forças de mercado, pautado para o CIPP, não leva em conta as necessidades da população residente, suas insatisfações e angústias. É oferecida a possibilidade de "mudarem de lugar", para que não sejam obstáculos ao crescimento econômico. Reassentamentos ou indenizações pelas "benfeitorias", uma vez que a terra foi decretada de utilidade pública, são as opções que oferecem.

Conforme Porto ${ }^{9}$, uma expressiva parcela das causas de mortalidade no Brasil é decorrente das desigualdades sociais de grande parcela da população excluída dos benefícios do desenvolvimento, recaindo sobre essa mesma parcela as piores condições de trabalho, moradia e vida, com suas implicações nos diversos tipos de doenças. $\mathrm{O}$ autor reforça que esta é uma situação e uma questão de injustiça ambiental.

Com a globalização, as realidades vividas em pequenas comunidades se universalizam, o contexto vivido no local torna-se transcultural e as estruturas de poder remetem a estratégias empresariais mundializadas. A forma como as populações são reassentadas, as indenizações inadequadas, a falta de cumprimento das promessas governamentais são fatos presentes em diversas partes do mundo. A execução de projetos de infraestrutura, apresentados como obras necessárias ao "progresso e à modernização", para melhorar as condições de vida da sociedade como um "todo", é o discurso do centro de poder nacional ou regional e das agências multilaterais ${ }^{10}$.

A comunidade em questão vive o dilema de não querer sair do seu lugar, a intranquilidade e a insegurança sobre o seu destino. Alguns capitu- lam, vendem suas terras, outros resistem, buscam apoio, organizam-se.

\section{O progresso e as mudanças no modo de vida tradicional - do trabalho no carnaubal, lavouras e farinhadas à edificação das firmas - tempos de incertezas, desfechos previsíveis}

Identificamos nas falas dos sujeitos, as preocupações relacionadas ao futuro dos trabalhadores da comunidade. Denotam a consciência da instabilidade que esse tipo de trabalho representa, diante das formas tradicionais de sobrevivência da comunidade ao longo do tempo.

O progresso está chegando e dando emprego, mas está acabando com muito serviço que já tinha como as plantações e o carnaubal. As famílias daqui sempre trabalharam na agricultura e no carnaubal, que era um serviço pesado, um serviço sofrido, mas era muito bonito. Era um serviço que eles lucravam muito. Hoje você pode procurar uma pessoa para trabalhar, capinar uma plantação que não acha mais. Hoje estão acabando com o carnaubal! É um serviço tradicional que está acabando.

[...] as firmas estão vindo, os empregos tão vindo, mas quando acabar os empregos da firma, esse povo que não tem estudo, que é de carnaubal de mão de obra pesada vão ficar desempregados. Tinha muito como eles manterem o nosso serviço de tradição, que era o carnaubal e as plantações. Além deles (empresas) estarem derrubando os carnaubais, estão tirando os trabalhadores [...] enquanto as firmas estão sendo construídas tem muito emprego, mas quando terminarem de levantar os prédios, como é que eles vão ficar?

Compreendemos que a mobilidade do capital, a nova divisão do trabalho e a reestruturação produtiva transformaram o mundo do trabalho de forma significativa. Em todo o processo histórico, as transformações nas relações sociais e no mundo do trabalho têm ocorrido, porém, nos últimos 30 anos, essas mudanças ocorrem com mais intensidade.

A região estudada apresenta as condições “ideais" para a concretização das mudanças produtivas e das novas relações sociais no mundo do trabalho. Tem terra, que não está disponível, mas tem o Estado para resolver essa questão, tem água, mão de obra barata e comunidades com dificuldades para organizar-se. As precárias relações de trabalho têm um campo fértil para proliferarem.

Os debates em torno das mudanças referentes ao mundo do trabalho apontam para alterações 
radicais que estão levando ao fim da centralidade do trabalho, principalmente em duas direções, conforme Organista ${ }^{11}$.

a) A primeira, como atividade ordenadora e fundadora da identidade coletiva, ou seja, a perda da dimensão subjetiva do trabalho enquanto categoria constituinte e constituidora de modos de agir, sentir, pensar, enfim, de uma conduta moral socialmente reconhecida;

b) A segunda, a diminuição de postos de trabalho fundada na regulamentação e no assalariamento, estabelecendo-se como tendência uma desconstrução desse processo, através de novos padrões de produção e organização de trabalho.

Ambas as tendências são complementares, conforme o autor citado e reconhecemos o impacto das mudanças ora em curso ocasionando uma maior flexibilização e precarização do trabalho, mas, este ainda permanece como categoria fundamental para compreender a sociedade contemporânea.

Segundo Vasconcelos ${ }^{12}$, a dialética trabalho e não trabalho no mundo contemporâneo traz à tona categorias que retirariam sua centralidade das relações sociais como mecanismo dissuasivo da luta de classes. Dessa forma, conforme o autor, qualquer que seja a teoria que embase a perda de centralidade do trabalho na configuração do Estado moderno, ao relativizá-lo como motor da vida humana e balizador da forma como ela se comporta sobre o planeta, reproduz a lenta trajetória da civilização humana na direção da igualdade de direitos.

Os trabalhadores, sejam os que residem em pequenas comunidades, sejam os migrantes em busca de empregos, convivem com a insegurança e instabilidades provenientes das relações de produção que se estabelecem nesse território, iludem-se ao considerarem-se detentores de direitos.

Eu acho que já mudou muita coisa desde que essa empresa chegou (termelétrica), o povo só pensa nessas firmas e se esquecem de cultivar o ambiente, as plantações, os carnaubais. Que eles estão com essa falsa ilusão de que esse emprego é melhor, que ganha mais. Eles não se dão conta de como é um trabalho escravo, só estão levando em conta o dinheiro, o salário que eles estão recebendo, mas em compensação [...] o que eles tão passando lá dentro! Eu creio que o trabalho que eles tinham aqui era muito mais digno, valia muito mais a pena.

Como é que vão estar esse povo daqui a dois anos? Muitos trabalham 2, 3 meses, a empresa coloca para fora, não querem dar o direito, aí eles ficam 1 mês, 2 meses em casa, vem outro emprego, contratam de novo e eles estão com essa esperança falsa de que vai ter emprego a vida toda, todo tempo elas vão empregar eles, eles não têm consciência de que esse aí é só o projeto de terraplanagem, da construção delas, e nem é até o final da construção, é só essa parte mesmo bem pesada.

As indagações das pessoas do grupo refletem um questionamento acerca da natureza da relação trabalhista que se estabelece, movida pela necessidade de trabalho e substituição das atividades produtivas. A submissão da classe trabalhadora gera cargas sociais, biológicas e psíquicas que refletem na relação comunitária, adentra as famílias e a sua dinâmica cotidiana. Repercutem na saúde uma vez que modifica as condições para que ela aconteça.

As transformações ambientais retratadas pelo grupo nos mostram não somente os danos ambientais de grande magnitude, mas a destruição de uma fonte de trabalho e riqueza presente nesse ecossistema. Conforme relatos do grupo, o carnaubal se constituía como importante fonte de renda para as famílias da comunidade. As atividades produtivas não estão mais vinculadas às características ecológicas do território, tampouco às vocações históricas da população. Adaptam-se às ofertas do mercado, mais restrito nesses tempos de crise, mais impositivo e que enfraquece os laços de solidariedade, deixando as pessoas inseguras quanto ao seu futuro.

Há uma preocupação das pessoas do grupo com essas questões e essas reflexões podem despertar a comunidade, no sentido de avançar para uma maior autonomia em processos organizativos unirem-se em busca do bem comum.

Para a produção acontecer, o trabalho humano e a exploração da natureza são elementos fundamentais e a degradação ambiental, as doenças, a desestruturação cultural e social das comunidades em que se inserem os processos produtivos, são repercussões presentes em um contexto de desigualdades.

As mulheres daqui sempre trabalharam em casa de farinha, bordados e em casa mesmo. Antigamente quase todo mundo bordava, era uma coisa que passava de mãe pra filha. Hoje eu não estou vendo mais. Elas trabalhavam com palha porque existia o carnaubal, está acabando o carnaubal e elas não podem mais comprar a palha. Tem uma senhora que ainda faz artesanato, mas agora como não tem mais a carnaúba, ela faz é de jornal, tentou criar outra maneira para não perder a cultura. As mulheres daqui sempre foram mais de cuidar do lar, trabalhar nas farinhadas, aí com essas empresas já estão começando a pensar em arranjar algum emprego nelas, são poucas! 
Hoje em dia quase não tem mais farinhada, antigamente era uma atrás da outra, quando terminava a roça de um começava a do outro, tinha trabalho direto.

Passei muitos anos trabalhando fora daqui, mais enricando os outros. [...] voltamos aposentados, com uma renda certa, para tirar o resto da nossa vida sem mendigar o pão. Só que, esse (desenvolvimento) de hoje é diferente do que eu fui fazer lá fora, porque lá não mexeu em nada nos bens da gente.

A substituição das atividades tem sido constantes conforme reflexão dos sujeitos. As mulheres, embora em menor quantidade, procuram se inserir nesse novo mercado, provocadas pelas transformações em curso. A implantação de empreendimentos na comunidade tem contribuído para processos de mudanças nos hábitos e costumes, principalmente no que se refere às atividades produtivas.

O trabalho nas farinhadas, que agregava a comunidade, estimulava a solidariedade vem rareando conforme os participantes do grupo. A sociabilidade desses momentos era sempre prazerosa e se realizava com alegria.

\section{Utopias do desenvolvimento: emprego digno, renda garantida, uma inversão da concepção de trabalho - de produtor a recurso produtivo}

O grupo reconhece que a população da comunidade não se enquadra enquanto força de trabalho para esses processos produtivos que aportam no território. Enquadram-se nesse primeiro momento, quando há a necessidade de uma mão de obra sem especialização. A proposta oficial de desenvolvimento, colada ao interesse do grande capital, não leva em conta as necessidades da população, que se encontra vulnerabilizada pelas desapropriações de moradias, e modificadas as condições de trabalho, tornando-se inseguras quanto ao seu futuro.

A transição que se opera em uma comunidade, com práticas agrícolas que vem tentando adaptar às profundas transformações, encontra uma força de trabalho despreparada para as novas necessidades dos processos produtivos que se instalam nesse território.

Toda essa situação tem impacto direto e indireto na saúde nos diversos grupos populacionais ali residentes e na sustentabilidade das famílias. As grandes forças motrizes do processo saúdedoença estão, hoje, fortemente associadas a políticas governamentais, sejam no campo do de- senvolvimento, sejam nas políticas específicas do setor saúde.

As mulheres agora deixam de cuidar das suas casas prá trabalhar nessas firmas, serem cozinheiras. E pelo que a gente escuta, é outra escravidão, que é mais de mil pratos prá lavar, uma mulher só. Como a M. me contou, que as mãos dela, quando chegava em casa, tava toda arrancando os pedaços, por conta dos produtos. Eles fazem comida muito gordurosa, então tem que ser produto que limpe rápido os pratos, e ela ficava até tarde lavando lá. Tanto para homem quanto para a mulher, está sendo uma coisa muito escrava e o povo não se dá conta.

Porque, levando em conta o trabalho: a juventude daqui só trabalha de servente, e servente é a parte mais ruim que tem, é o pesado. O encarregado tá lá, mas o encarregado tá prá mandar. É só servente mesmo, acabou a parte bruta tão tudo na rua. Não tem um curso profissionalizante. Por exemplo, uma máquina dá problema, tem que vir um cara lá de São Paulo, não sei de onde. Tem que vir, pois não tem pessoa capacitada prá isso. E eu acho que antes de vir o progresso tem que preparar a comunidade, deveria ser assim, mas infelizmente...

Os participantes do grupo deixam claro em seus discursos a falta de formação das pessoas da comunidade, que reflete na situação de jovens que, ao invés do direito de estudar, resta-lhes a luta pela sobrevivência, a submissão a serviços que não faziam parte das suas vidas até então.

\section{Considerações Finais}

A implantação de um processo de desenvolvimento econômico numa comunidade traz impactos de grande magnitude com fortes interferências na organização comunitária e na saúde dos habitantes do lugar, principalmente dos trabalhadores. Concluímos isto a partir desta pesquisa, e, ainda, que os determinantes socioambientais da saúde se manifestam através do acirramento das desigualdades, das políticas governamentais truculentas e equivocadas, da racionalidade lucrativa das grandes corporações.

As políticas econômicas interferem na vida, alterando as dinâmicas comunitárias, prejudicando a saúde, pois causam adoecimentos e sofrimentos que extrapolam a capacidade do setor saúde para responder às novas necessidades, que são, em alguns casos, agudas, em outros, crônicas.

Observamos que a atuação da atenção primária é insuficiente em relação à realização de ações de saúde do trabalhador, e estas também não são desenvolvidas por outros pontos de atenção da 
rede assistencial. O território, portanto, não está contemplado com novos estabelecimentos de saúde, ou ampliação da formação e qualificação dos profissionais para atuar diante dos agravos relacionados ao 'novo trabalho'. Há um distanciamento do setor dessas questões que se concretizam com a chegada dos empreendimentos e modificações no sistema produtivo local.

Apesar das transformações advindas com o modelo de desenvolvimento econômico, proporcionar profundas mudanças no modo e estilo de viver das comunidades, principalmente dos trabalhadores, sejam esses rurais ou urbanos, não possuem em seu bojo perspectivas fundamentais para a atuação crítica desses trabalhadores, potencializando sua autonomia e cidadania. Há um descompasso, todavia, com o desenvolvimento de políticas públicas no que se refere à proteção e promoção à saúde nesses territórios.

As transformações ocorridas no nível local, decorrentes de novas formas de trabalho, ocasionam novos problemas de saúde, promovendo necessidades de aprendizagens para as comunidades atingidas, trabalhadores, profissionais da saúde, assim como a participação da academia no que

\section{Referências}

1. Zhouri A, Zucarelli MC. Mapa dos Conflitos Ambientais no Estado de Minas Gerais- Notas Preliminares de Uma Pesquisa em Andamento. In: IV Encontro Nacional da ANPPAS; 04 a 06 de junho de 2008; Brasília. p. 1-15.

2. Rigotto RM. A ideologia do desenvolvimento: ascensão, crise e horizontes de uma crença moderna. In: Rigotto RM. O "progresso" chegou. E agora? As tramas da (in)sustentabilidade e a sustentação simbólica do desenvolvimento [tese]. Fortaleza: Universidade Federal do Ceará; 2004. p. 74-79.

3. Ribeiro GL. Poder, redes e ideologia no campo do desenvolvimento. Novos Estudos - CEBRAP 2008; (80): 109-125.

4. Young CEF, Lustosa MCJ. A questão ambiental no esquema centro-periferia. Economia 2003; 4(2):201-221.

5. Bosi MLM, Mercado FJ. Pesquisa qualitativa de serviços de saúde. Rio de Janeiro: Vozes; 2004.

6. Minayo MCS, Sanches O. Quantitativo-qualitativo: oposição ou complementaridade? Cad Saude Publica 1993; 9(3):239-262.

7. Ressel LB, Gualda DMR, Gonzáles RMB. Grupo focal como estratégia para coletar dados de pesquisa em enfermagem. Int J Qual Methods 2002 [acessado 2009 maio 09]; 1(2): [cerca de 29 p.]. Disponível em: http://www. ualberta.ca/ iiqm/backissues/1_2Final/pdf/ressel.pdf concerne à investigação e elaboração de estudos.

Consideramos que o processo de pesquisa deflagrado e vivenciado por um período de dois anos, utilizando a pesquisa participante como abordagem metodológica, revelou-se um instrumento importante de aprendizados conjuntos e crescimento coletivo, em que o processo se constituiu como o ponto mais relevante do desenvolvimento da pesquisa, muito mais que os resultados.

\section{Colaboradores}

MGV Bezerra e VM Pessoa trabalharam na concepção da pesquisa, delineamento metodológico e análise dos dados e na redação e revisão crítica. RM Rigotto se responsabilizou pela revisão crítica e aprovação da versão a ser publicada. FVE Silva colaborou na pesquisa de campo e na metodologia.
8. Gill R. Análise de Discurso. In: Bauer MW, Gaskell G, organizadores. Pesquisa Qualitativa com Texto, Imagem e Som: um manual prático. Petrópolis: Vozes; 2008. p. 244-271.

9. Porto MFS. Saúde do Trabalhador e o desafio ambiental: contribuições do enfoque ecossocial, da ecologia política e do movimento pela justiça ambiental. Cien Saude Colet 2005; 10(4):829-839.

10. Almeida AWB. Refugiados do Desenvolvimento: os deslocamentos compulsórios de índios e camponeses e a ideologia da modernização. Rev Travessia 1996; (maio/ago):30-35.

11. Organista JHC. O Debate sobre a Centralidade do Trabalho. São Paulo: Expressão Popular; 2006.

12. Vasconcelos LCF. Saúde, trabalho e desenvolvimento sustentável: apontamentos para uma Política de Estado [tese]. Rio de Janeiro: Fiocruz; 2007.

Artigo apresentado em 14/07/2014

Aprovado em 14/07/2014

Versão final apresentada em 15/07/2014 